\title{
CONSELHO DE CLASSE COM PARTICIPAÇÃO ESTUDANTIL: COMPREENSÕES SOBRE AVALIAÇÃO DA APRENDIZAGEM
}

RUBIA CAVALCANTE VICENTE MAGNATA' ANA DE FÁTIMA PEREIRA DE SOUSA ABRANCHES"

I Universidade Federal Rural de Pernambuco (UFRPE), Recife-PE, Brasil; rubia.cv@hotmail.com

II Programa de Pós- Graduação em Educação, Culturas e Identidades (PPGECI), Universidade Federal Rural de Pernambuco (UFRPE) e Fundação Joaquim Nabuco (Fundaj), Recife-PE, Brasil; ana.abranches@fundaj.gov.br

\section{RESUMO}

Este artigo tem como objetivo analisar a participação de estudantes em conselho de classe e os possíveis significados dessa para a avaliação da aprendizagem. Partiu-se da compreensão de que tal participação e a interação com os docentes nesse espaço podem se constituir como elemento de fundamental importância para favorecer a autonomia e o desenvolvimento dos estudantes e, ainda, outras práticas de aprendizagens e avaliação. Apoiado na pesquisa de natureza qualitativa, foi realizado um estudo de caso em uma escola que possui conselho de classe com participação dos estudantes. As compreensões dos sujeitos que integram o conselho de classe revelam que a participação estudantil consegue proporcionar uma relação mais horizontal, de diálogo e negociação entre docentes e estudantes, o que favorece algumas reflexões e mudanças nos sujeitos que compõem o processo de ensino e aprendizagens.

PALAVRAS-CHAVE CONSELHO DE CLASSE • PARTICIPAÇÃO DO ALUNO - AVAliAÇÃo dA APRENDIZAGEM - RELAÇÃO PROFESSOR-ALUNO. 


\section{CONSEJO DE CLASE CON PARTICIPACIÓN ESTUDIANTIL: COMPRENSIONES SOBRE LA EVALUACIÓN DEL APRENDIZAJE}

RESUMEN

Este artículo tiene el objetivo de analizar la participación de estudiantes en el consejo de clase y sus posibles significados para evaluar el aprendizaje. Se partió de la comprensión de que tal participación y la interacción con los docentes en dicho espacio pueden constituir un elemento de fundamental importancia para favorecer la autonomía y el desarrollo de los alumnos, así como otras prácticas de aprendizajes y evaluación. En base a una investigación de naturaleza cualitativa, se llevó a cabo un estudio de caso en una escuela que posee un consejo de clase con la participación de estudiantes. Las comprensiones de los miembros del consejo de clase revelan que la participación estudiantil logra proporcionar una relación más horizontal, de diálogo y negociación entre docentes y alumnos, lo que favorece algunas reflexiones y cambios en los individuos que componen el proceso de enseñanza y aprendizaje.

PALABRAS CLAVE CONSEJO DE CLASE - PARTICIPACIÓN DEL ALUMNO • EVALUACIÓN DEL APRENDIZAJE • RELACIÓN PROFESOR-ALUMNO.

\section{CLASS COUNCIL WITH STUDENT PARTICIPATION: UNDERSTANDINGS ABOUT LEARNING EVALUATION \\ ABSTRACT}

This article aims to analyze student participation in class councils and its possible meaning for learning evaluation. It was based on the understanding that such participation and interaction with teachers in this context can constitute an essential element which favors student autonomy and development, as well as other learning and evaluation practices. Based on qualitative research, a case study was carried out in a school with a class council having student participation. The understandings of the subjects in the class council reveal that student participation can provide a more horizontal relationship, dialogue and negotiation between teachers and students. This favors reflections and changes in the subjects that comprise the teaching and learning process.

KEYWORDS CLASS COUNCIL • STUDENT PARTICIPATION • LEARNING ASSESSMENT • TEACHER-STUDENT RELATIONSHIP. 


\section{INTRODUÇÃO}

A avaliação educacional é um tema bastante discutido e não há dissenso quanto à sua importância para a educação. Esteja fundamentada numa concepção tradicional, em que se objetiva medir e verificar as aprendizagens, tendo como eixo a dicotomia entre o certo e o errado para ratificar a seleção e a meritocracia, ou esteja apoiada numa concepção mais humana e formativa, que compreende o estudante como sujeito participante de seu processo de construção do conhecimento, a avaliação sempre é vista e entendida como elemento indispensável aos fins educacionais.

Em torno do discurso neoliberal, é necessário avaliar o quanto a escola, os professores e os estudantes estão correspondendo ao que lhes é solicitado, por meio dos programas e das políticas educacionais que são criados e implementados a fim de assegurar maior eficiência e produtividade educacional. Nesse sentido, as escolas são submetidas a avaliações externas e internas, e os seus resultados são comparados e publicados para fomentar o jogo desigual da competição e do mercado de trabalho. Desigual, porque, no fim de tudo, a 
responsabilização pelo insucesso escolar recai sobre os professores e os estudantes, por meio da validação da meritocracia.

Por essa perspectiva, os estudantes são compreendidos como seres que precisam adquirir mais habilidades e mais competências para lidar com o mercado de trabalho cada vez mais especializado e exigente, e os professores são vistos como os profissionais que devem fornecer maior conhecimento e capacitação aos estudantes. Assim, o processo de ensino e de aprendizagem precisa estar polarizado em grandes quantidades de conteúdos e em avaliações que verifiquem e certifiquem essa aquisição de conhecimentos. Os resultados dessas avaliações geralmente são desconectados da realidade do estudante e não conseguem enxergar as aprendizagens sendo construídas processualmente, tampouco conseguem observar e compreender as diferentes dimensões que compõem a complexidade do que é ser humano. O que importa nesse processo é o resultado quantificável, ou seja, os números e as posições dentro de uma escala ou padrão pré-estabelecido.

Nesse contexto, a avaliação da aprendizagem escolar serve como instrumento de seleção e exclusão social à medida que separa aquele sujeito mais preparado, e certamente aquele que teve mais acesso a bens culturais e materiais, daqueles que tiveram pouca ou nenhuma oportunidade de acessar esses bens.

No entanto, se acreditamos em uma concepção de educação que pode conduzir o ser humano à formação integral, a partir das experiências de aprendizagens mediadas por um contexto escolar que propicia diálogo, interação e negociação entre os sujeitos envolvidos com o ato de ensinar e aprender, a avaliação da aprendizagem escolar serve como um instrumento de grande valor para obtenção de informações úteis à melhoria do processo de ensino e aprendizagem:

No âmbito educativo, a avaliação deve ser entendida como atividade crítica de aprendizagem, porque se assume que a avaliação é aprendizagem no sentido de que por meio dela adquirimos conhecimento. $O$ professor aprende para conhecer e para melhorar a prática docente em sua complexidade, bem como para colaborar na aprendizagem do 
aluno, conhecendo as dificuldades que deve superar, o modo de resolvê-las e as estratégias que coloca em funcionamento. $O$ aluno aprende sobre e a partir da própria avaliação e da correção, da informação contrastada que o professor oferece-lhe, que será sempre crítica e argumentada, mas nunca desqualificadora, nem punitiva. (ÁLVAREZ MÉNDEZ, 2002, p. 14)

Compreendendo a avaliação como instrumento de acompanhamento e de regulação das aprendizagens, ou seja, como instrumento em que o educador observa e segue de perto o desenvolvimento das aprendizagens, mas com a qual também vai criando, recriando e/ou descartando estratégias em função destas, a avaliação será fundamentalmente formativa.

De acordo com Perrenoud (1999), não há dúvidas de que a avaliação pode auxiliar a aprendizagem do aluno, e de que há muito tempo nas escolas educadores vêm lutando contra as notas, procurando colocar a avaliação mais a serviço dos alunos do que do sistema. Sendo assim, pouco a pouco a escola muda e a avaliação também evolui, de maneira que falar de avaliação formativa já não significa mais falar de atributos de seres de outros planetas e, desse modo,

[...] talvez passemos - muito lentamente - da medida obsessiva da excelência a uma observação formativa a serviço da regulação das aprendizagens. Todavia, nada está pronto! (PERRENOUD, 1999, p. 10)

É necessário percorrer um longo caminho para o rompimento com a cultura tradicional de avaliação da aprendizagem e para a construção de uma cultura de avaliação transformadora e formativa, pois, segundo Perrenoud (1999, p. 11), a avaliação escolar está situada entre duas lógicas, uma tradicional e outra emergente. Na lógica tradicional, a avaliação das aprendizagens na escola está associada à criação de hierarquias de excelência e, na lógica emergente, direciona-se a uma avaliação formativa, mais integrada à ação pedagógica cotidiana, de modo que:

A avaliação tradicional, não satisfeita em criar fracasso, empobrece as aprendizagens e induz, nos professores, 
didáticas conservadoras e, nos alunos, estratégias utilitaristas. A avaliação formativa participa da renovação global da pedagogia, da centralização sobre o aprendiz, da mutação da profissão do professor: outrora dispensador de aulas e de lições, o professor se torna criador de situações de aprendizagem "portadoras de sentido e de regulação". (PERRENOUD, 1999, p. 18)

E, embora a escola, de um modo geral, ainda esteja muito ligada à prática de uma avaliação tradicional, uma concepção diferente de educação, que busca formar indivíduos autônomos, críticos, reflexivos, solidários, responsáveis, comprometidos e conscientes com o meio social e político em que vivem, vem solicitando um novo modo de conceber e realizar a avaliação das aprendizagens dos estudantes.

De acordo com Luckesi $(2008$, p. 81), se queremos que a avaliação sirva à democratização do ensino, de modo que todos os estudantes possam desenvolver as suas aprendizagens e formação integral, é preciso "modificar a sua utilização de classificatória para diagnóstica”. Desse modo, a avaliação não fica a serviço da aprovação ou reprovação do aluno, mas se torna instrumento de compreensão para saber em que estágio de aprendizagem o estudante se encontra para, a partir daí, tomarem-se decisões assertivas para melhorar o seu desenvolvimento. Ainda segundo Luckesi (2008), a avaliação como instrumento diagnóstico para o avanço das aprendizagens terá funções de autocompreensão do sistema de ensino, de autocompreensão do professor e do aluno.

Nesse sentido, a avaliação realizada com o estudante dá subsídios para que o sistema de ensino venha a se autoavaliar a partir do alcance dos objetivos estabelecidos. O professor, por sua vez, através do acompanhamento das aprendizagens dos alunos, pode também avaliar o seu trabalho docente. E o educando estará permanentemente descobrindo em que nível de aprendizagem está, tomando consciência do seu limite e das necessidades de avançar em seu percurso. Porém, para que a avalição funcione para o estudante como meio de autocompreensão, é preciso que tenha caráter de avaliação participativa, no sentido de que professor, a partir dos 
instrumentos adequados de avaliação, venha a discutir com os alunos o estágio de aprendizagem no qual se encontram, e com isso consiga equacionar as dificuldades encontradas. Desse modo, "estaríamos, pois, superando o modo de agir comum e autoritário que vem atravessando as atividades de avaliação da aprendizagem escolar, de forma antidemocrática" (LUCKESI, 2008, p. 84).

Ainda refletindo sobre o papel da escola e o tipo de avaliação que fundamenta sua prática, encontramos em Álvarez Méndez (2002, p. 62) a necessidade de questionar os objetivos que fundamentam a educação e o tipo de ensino que a escola concretiza: "seleção/exclusão ou ascensão das pessoas pelo acesso ao saber via aprendizagem e melhoria ou aperfeiçoamento da competência individual?".

Compreendendo a educação como um processo de acesso democrático ao conhecimento e à ascensão das pessoas, é necessário transformar a avaliação numa atividade de conhecimento em que se garanta uma formação contínua tanto do educando quanto do educador. Sendo assim, a tarefa de avaliar "é conhecer, é contrastar, é dialogar, é indagar, é argumentar, é deliberar, é raciocinar, é aprender” (ÁLVAREZ MÉNDEZ, 2002, p. 63). E ainda:

Por meio da avaliação, queremos conhecer a qualidade dos processos e dos resultados. E, em educação, queremos conhecer para valorizar os processos que produzem certos resultados e intervir a tempo, se necessário, com a sincera intenção de assegurar o êxito dos que participam do mesmo processo educativo - decisão que brota da própria atividade avaliadora. Este deverá ser o sentido da avaliação formativa, que também será contínua e pessoal. (ÁLVAREZ MÉNDEZ, 2002, p. 64)

Diferentemente de uma concepção tradicional, que busca avaliar as aprendizagens com a intenção de corrigir, punir e classificar, a avaliação formativa se constitui como aquela que, por meio da observação e intervenção do professor, com um acompanhamento próximo e individualizado, torna-se capaz de assegurar a melhoria do processo de ensino e aprendizagem. 
Segundo esse autor (ÁLVAREZ MÉNDEZ, 2002), só é possível falar com propriedade em avalição formativa quando a avaliação atua a serviço do conhecimento e da aprendizagem, e de outros interesses formativos, de maneira que se aprende com ela à medida que transformamos o momento da correção em atividade de conhecimento e em ato de aprendizagem. Apenas ao assegurar a aprendizagem é que se assegura a avaliação formativa.

Para se configurar como formativa, Álvarez Méndez (2002) ressalta algumas especificidades, entre as quais: a necessidade de a avaliação ser democrática, transparente, negociada, estar a serviço do processo de ensino e aprendizagem - principalmente de quem aprende - , ser uma atividade motivadora e orientadora, nunca punitiva.

Perrenoud (1999, p. 78) também aponta que a avaliação formativa se relaciona diretamente com o desenvolvimento e a melhoria do processo de aprendizagem:

É formativa toda avaliação que ajuda o aluno a aprender
e a se desenvolver, ou melhor, que participa da regulação
das aprendizagens e do desenvolvimento no sentido de
um projeto educativo.

Na avaliação formativa, existe sempre a intenção de regulação, sempre se procura observar o que já foi construído em termos de conhecimentos e o que ainda falta, com o objetivo de realizar as intervenções necessárias para potencializar as aprendizagens em andamento (PERRENOUD, 1999, p. 103).

Contribuindo para essa reflexão, Hoffmann (2014) também aponta que, numa perspectiva de acompanhamento e melhoria do desenvolvimento das aprendizagens, a avaliação deva ser mediadora, na qual a qualidade da educação é sinônimo de desenvolvimento máximo de cada aluno, visando permanentemente ao "vir a ser" de cada um:

Assim, o significado primeiro e essencial da ação avaliativa mediadora é o "prestar muita atenção", eu diria "pegar no pé" de cada um dos alunos, insistindo em conhecê-lo melhor, em entender sua fala, seus argumentos, teimando em conversar com ele em todos os momentos, ouvindo 
todas as suas perguntas, fazendo-Ihe novas e desafiadoras questões, "implicantes", até, na busca de alternativas para uma ação educativa voltada para a sua autonomia moral e intelectual [...]. (HOFFMANN, 2014, p. 36-37)

A referida autora $(2014$, p. 72$)$ aponta alguns princípios coerentes com a ação da avaliação mediadora; um deles se refere a "oportunizar aos alunos muitos momentos para expressar suas ideias”. Embora Hoffmann (2014) esteja tratando do contexto da sala de aula, é possível considerar que esse princípio também pode ser aplicado ao conselho de classe, à medida que o consideramos como espaço de avaliação formativa, onde o diálogo e a troca de informações entre educadores e educandos podem favorecer um melhor desenvolvimento das aprendizagens dos estudantes.

Todavia, muito mais do que espaço para expressão de ideias, o conselho de classe traz em sua configuração a possibilidade de a avaliação ser conduzida por características de diagnóstico, de mediação, de negociação e de regulação das aprendizagens.

Quando os professores e os orientadores pedagógicos ou outros serviços ligados à aprendizagem podem trocar experiências e opiniões diferentes em torno do processo de formação do estudante, e quando a participação do estudante por meio das queixas, das dúvidas e até dos elogios favorece tanto a autoavaliação docente quanto a autoavaliação discente, o momento coletivo de avaliação no conselho de classe se torna extremamente rico e fecundo para a construção de práticas avaliativas formativas e aprendizagens significativas.

O conselho de classe como instância escolar responsável pelo acompanhamento do desenvolvimento do estudante, com a participação discente e orientado pela concepção de avaliação diagnóstica (LUCKESI, 2008), de avaliação como regulação (PERRENOUD, 1999), de avaliação mediadora (HOFFMANN, 2014) e de avaliação formativa (ÁLVAREZ MÉNDEZ, 2002), consegue direcionar o processo de ensino e aprendizagem a um nível superior, quebra barreiras de autoritarismo, rompe com a discriminação e a exclusão, torna a relação entre docentes e estudantes mais horizontal e mais 
dialogada, o que colabora substancialmente para a formação integral do educando.

A compreensão de construção da prática da avaliação formativa, na qual professores e estudantes podem juntos refletir e dialogar sobre o que vem sendo ou não construído em termos de aprendizagens, traz uma outra perspectiva para o conselho de classe, e é uma possibilidade de transformação no modo de pensar e agir desses sujeitos que compõem o ato de ensinar e aprender. Nesse sentido, o conselho de classe com a participação dos estudantes permite que todos os sujeitos presentes nesse espaço coletivo de avaliação se tornem colaboradores responsáveis quanto ao desenvolvimento do processo de ensino e aprendizagem:

Essa prática exercida no conselho de classe deve desempenhar um papel no sentido de mobilizar a avaliação na perspectiva de desenvolver um maior conhecimento a respeito do aluno e envolvê-lo no processo de forma a ser sujeito da educação e da avaliação. Aproveitar esse espaço para reflexão é direcionar um projeto democrático de atuação pedagógica, no qual a avaliação tem importância fundamental, não apenas para análise de resultados, mas para a retomada das dificuldades encontradas. Essa forma de organização de conselho de classe possibilita repensar mecanismos pedagógicos para avançar no ensino-aprendizagem, como conscientizar cada integrante que a ação coletiva é uma referência para o exercício da cidadania. (SANTOS, 2010, p. 309-310)

A participação do estudante em seu processo avaliativo coloca-o como sujeito que partilha com o educador a tarefa de pensar sobre o que se alcançou, o que ainda falta e quais as possibilidades de ação para alcançar maiores conhecimentos e experiências.

Partindo de uma concepção democrática, a proposta de um espaço coletivo de avaliação que tem a participação dos sujeitos envolvidos com o ato educativo consegue favorecer não apenas maior diálogo e interação, mas também o desenvolvimento das aprendizagens, na medida em que os estudantes presentes nessas reuniões podem colocar suas 
dificuldades e queixas no que diz respeito tanto à metodologia de ensino como à relação professor-aluno estabelecida em sala de aula.

Por outro lado, essa participação não deve ser compreendida apenas como presença; é preciso alteridade para refletir sobre o que está sendo solicitado, para modificar o que não está efetivamente ajudando no processo e aprendizagem, e ainda são necessários comprometimento e seriedade quanto ao seu papel enquanto sujeito ativo na construção do conhecimento:

Quando o aluno percorrer os diversos momentos das avaliações, com interesse e responsabilidade, passando de um sujeito passivo para um ativo, por intermédio da reflexão sobre seu papel e seus direitos como educando, estará buscando a qualidade na educação. O sentido da avaliação e sua relação com o agente direto, o aluno, devem ser completas, interferindo sobre todas as dimensões, imprescindível para ajudar a responder às demandas da vida, a fim de gerar novos conhecimentos. (SANTOS, 2010, p. 306)

Numa perspectiva de avaliação como prática formativa, reconhecemos o conselho de classe como um encontro formal e sistematizado, que pode proporcionar aos docentes e orientadores pedagógicos reflexões a partir dos diagnósticos levantados, favorecer a mobilização, a criação e a reformulação de estratégias pedagógicas que venham a possibilitar o maior e melhor desenvolvimento e construção de conhecimentos e experiências educativas (afetivas e cognitivas) em função do educando e, ainda, favorecer a tomada de decisões mais justas e responsáveis frente à avaliação das aprendizagens dos estudantes.

Como espaço de diálogo e participação, o conselho de classe que tem a participação dos estudantes pode permitir também a estes o direito de apresentar suas queixas e necessidades. No entanto, essa participação vai solicitar ao estudante a compreensão de que o lugar ocupado nesse espaço não se refere ao papel de vítima, mas que lhe exige um comprometimento com seu processo de aprendizagem a 
partir de sua autoavaliação e das colocações e intervenções feitas pelo conjunto de profissionais que compõem esse espaço coletivo de avaliação.

Refletindo sobre a importância da atuação de um conselho de classe participativo, que venha a fomentar processos avaliativos mais formativos dentro do ambiente escolar, o objetivo desse estudo é analisar a participação dos estudantes no conselho de classe e os significados para a avaliação das aprendizagens.

O interesse para este estudo surgiu de nossa pesquisa anterior (MAGNATA; SANTOS, 2015) sobre conselho de classe, que buscou analisar esse espaço coletivo de avaliação como possibilidade para a avaliação formativa. Tal estudo revelou que, segundo os professores entrevistados na ocasião da pesquisa, a participação dos estudantes nas reuniões do conselho de classe era um elemento de fundamental importância tanto para a avaliação das aprendizagens dos estudantes feitas pelos docentes quanto para a avaliação da própria prática docente. Como resultado da pesquisa, a participação discente no conselho de classe levantou novos questionamentos: de que maneira a participação dos estudantes se materializa no conselho de classe? Quais os significados e as compreensões dessa participação para professores e alunos? De que maneira a participação dos estudantes no conselho de classe contribui para os processos de avaliação das aprendizagens?

Para responder a essas questões, retornamos ao mesmo campo empírico da pesquisa anterior, uma vez que a escola estudada tem um conselho de classe com configurações participativas, ou seja, tem a participação de todos os estudantes de uma turma em suas reuniões, o que se torna um diferencial entre a grande maioria das escolas públicas atuais.

\section{PROCEDIMENTO METODOLÓGICO}

Compreendendo a escola como espaço dinâmico, carregado de símbolos, culturas, concepções e ações de diferentes sujeitos, buscamos coletar dados significativos e pertinentes para o contexto e o nosso objetivo geral: analisar a representação e participação dos estudantes no conselho de classe e os 
significados para a avaliação da aprendizagem e para a gestão democrática na escola. Assim, optamos, dentro da perspectiva de pesquisa qualitativa, pelo estudo de caso, que, segundo Gil (2010, p. 37), “consiste no estudo profundo e exaustivo de um ou poucos objetos, de maneira que permita seu amplo e detalhado conhecimento". E que, segundo Chizzotti (2006, p. 102), corresponde a:

Uma caracterização abrangente para designar uma diversidade de pesquisas que coletam e registram dados de um caso particular ou de vários casos a fim de organizar um relatório ordenado e crítico de uma experiência, ou avaliá-la analiticamente, objetivando tomar decisões a seu respeito ou propor uma ação transformadora.

Para a coleta de dados, foram feitas observações nos conselhos de classe para acompanhamento pedagógico das turmas do $9^{\circ}$ ano do ensino fundamental e do $3^{\circ}$ ano do ensino médio e ainda realizamos entrevistas com 11 professores das diferentes áreas de conhecimento, a saber: Ciências Exatas e da Natureza; Comunicação e Expressão e Educação Artística; e Estudos Sociais. As entrevistas foram previamente agendadas e realizadas nos dias e horários conforme disponibilidade dos mesmos. Elas foram gravadas em aparelho celular para posterior transcrição com a autorização dos professores, com exceção de uma professora que informou que, para sentir-se mais à vontade, preferia não gravar a entrevista; nesse caso, anotamos as respostas em diário de campo. Os critérios de escolha dessa amostra foram: 1) tempo de serviço na escola; 2) serem professores efetivos; 3) exercício de uma outra função ou cargo no colégio para além da docência; 4) serem professores de diferentes áreas de conhecimento; 5) e disponibilidade de participação.

O tempo de experiência dos professores entrevistados na escola varia em média de um a trinta anos de docência. Todos os entrevistados exercem ou já exerceram uma outra função/cargo no colégio, como, por exemplo, direção, coordenação de setor, coordenação de projetos, supervisão de turma, chefia de área, coordenação de ensino fundamental e médio, entre outros. 
Dos 11 professores entrevistados, dois têm pós-doutorado, cinco têm doutorado, um tem doutorado em andamento, e dois têm mestrado. Há ainda um docente do qual não conseguimos a informação. ${ }^{1}$ Foram realizadas também entrevistas com duas técnicas educacionais, uma na função de pedagoga, outra na função de psicóloga, atuando respectivamente no Serviço de Orientação Educacional (SOE) e no Serviço de Orientação e Experimentação Pedagógica.

A amostra de estudantes representantes de turma tem o quantitativo de seis participantes. São dois representantes do $9^{\circ}$ ano do ensino fundamental, dois do $2^{\circ}$ ano e mais dois do $3^{\circ}$ ano do ensino médio, sendo que, nesse último, são dois representantes da mesma turma, ao contrário dos demais, que são um para cada turma. E ainda, desse total, dois estudantes representantes de turma participaram por meio de entrevista semiestruturada e quatro estudantes representantes de turma participaram via questionário semiestruturado, devido à dificuldade que encontramos em realizar as entrevistas. Importante esclarecer que as perguntas das entrevistas são as mesmas utilizadas no questionário.

O estudo dos dados coletados foi realizado por meio de análise de conteúdo, que, segundo Bardin (2009, p. 44), pode ser designada como:

Um conjunto de técnicas de análise das comunicações visando obter por procedimentos sistemáticos e objectivos de descrição do conteúdo das mensagens indicadores (quantitativos ou não) que permitam a inferência de conhecimentos relativos às condições de produção/recepção (variáveis inferidas) destas mensagens.

Segundo Chizzotti (2006, p. 98), o objetivo da análise de conteúdo é "compreender criticamente o sentido das comunicações, seu conteúdo manifesto ou latente, as significações explícitas ou ocultas". Buscando analisar como a participação dos estudantes no conselho de classe é compreendida pelos diferentes sujeitos que compõem esse espaço coletivo de avaliação, as categorias de análise foram determinadas a partir das falas dos participantes da pesquisa. 
2 Temos autorização do Serviço de Orientação e Experimentação Pedagógica para identificar a instituição escolar pesquisada.
Para os trechos dos registros de observações nos conselhos de classe e para os trechos das entrevistas, fizemos o uso de letras: docente (D), estudante (E), técnico educacional (TE). As letras foram seguidas de um número a depender do quantitativo dos participantes, por exemplo: Docente 1 (D1), Docente 2 (D2), Estudante 1 (E1), Estudante 2 (E2), Técnico Educacional 1 (TE1), e assim por diante.

\section{ANÁLISE DOS DADOS}

Por ter como diferencial um conselho de classe que tem a participação de todos os estudantes de uma turma, este estudo tem como campo empírico o Colégio de Aplicação da Universidade Federal de Pernambuco (UFPE). ${ }^{2}$

De acordo com seu projeto político-pedagógico institucionalizado (PPPI, 2015), o colégio tinha, no ano de 2014, um total de 44 professores efetivos, com regime de trabalho de 40 horas, com dedicação exclusiva, com formação acadêmica em: mestrado (17 docentes), doutorado (16), especialização (10) e graduação (1) e ainda 11 professores substitutos com regime de trabalho de 20 ou 40 horas sem dedicação exclusiva. O corpo discente é composto por 420 alunos, sendo 240 alunos do ensino fundamental ( $6^{\circ}$ ao $9^{\circ}$ ano) e 180 alunos do ensino médio ( $1^{\circ}$ ao $3^{\circ}$ ano).

A escola realiza processo seletivo para ingresso no $6^{\circ}$ ano do ensino fundamental, no qual os candidatos fazem provas de Matemática, Português e Produção Textual (Redação). Segundo o PPPI (2015) do colégio, o processo seletivo tem, em média, por ano, um total de 1700 candidatos, a fim de preencher o quantitativo de 55 vagas, o que demonstra a alta concorrência (30,9 candidatos para uma vaga) e o grande interesse de pais e estudantes por essa instituição de ensino. Importante informar que, quando há casos de evasão ou retenção, o que dificilmente ocorre, também existe seleção de estudantes por meio de provas.

O colégio, por estar inserido no contexto da Universidade e atuando como espaço de ensino, pesquisa e extensão, bem como ser campo de estágio e formação docente para os estudantes das diversas licenciaturas, além do fato de seu 
corpo docente e técnico ter alto nível de formação e o corpo discente corresponder a candidatos selecionados por um processo de avaliação seletivo e meritocrático, é uma instituição escolar que se diferencia da grande maioria das escolas públicas do país. O modo de funcionamento e organização, com a participação dos estudantes no conselho de classe desse colégio, também se revela como um elemento que distingue essa escola.

No entanto, é preciso analisar como a dinâmica da participação estudantil acontece no conselho de classe dessa instituição de ensino e como tem sido compreendida pelos docentes, pelos técnicos educacionais e pelos próprios estudantes, a fim de entender se essa dinâmica participativa consegue de alguma forma favorecer que a prática avaliativa se torne mais formativa.

Importante explicitar, nesse momento, que o conselho de classe do Colégio de Aplicação da UFPE está organizado em cinco reuniões durante o ano letivo, dispostas do seguinte modo:

a. $1^{\circ}$ conselho de classe - Prognóstico (sem a presença dos estudantes), ocorre no início do ano letivo para fins de planejamento e conhecimento da turma;

b. $2^{\circ}, 3^{\circ}$ e $4^{\circ}$ conselhos de classe - ocorrem durante o ano letivo, servem para realizar o acompanhamento pedagógico das aprendizagens dos estudantes (dividem-se em dois momentos: um primeiro momento com a presença dos estudantes e um segundo momento sem a presença dos estudantes);

c. e o $5^{\circ}$ conselho de classe - ocorre ao final do ano letivo e serve para realizar a promoção (aprovação) ou retenção (reprovação) dos estudantes.

Desse modo, observa-se que, embora todos os estudantes de uma turma possam e devam participar das reuniões do conselho de classe para acompanhamento pedagógico, a participação deles se restringe ao primeiro momento do conselho de classe, mesmo a escola suspendendo as aulas nos dias destinados aos conselhos e considerando essa atividade no calendário escolar como dia letivo.

O conselho de classe para acompanhamento pedagógico da escola, de modo geral, funciona da seguinte forma: 
no primeiro momento, o(a) supervisor(a) de classe que está encarregado de coordenar o conselho abre a reunião com a leitura do texto coletivo da turma, tarefa que geralmente é feita pelo representante de turma. Em seguida, é aberto espaço para que os demais estudantes, caso queiram acrescentar ou enfatizar algo, possam falar. Logo após, abre-se a fala para os professores, os quais, de modo geral, respondem ao que foi colocado pelos estudantes.

$\mathrm{O}$ que mais se evidenciou nesses momentos observados foi a predominância de uma discussão em torno de questões comportamentais dos estudantes. E, embora nesse momento os estudantes façam, além de uma autoavaliação da turma, avaliações sobre os docentes, observou-se que os estudantes acabam sendo o centro das avaliações, na medida em que eles mesmos colocam, em suas autoavaliações, a necessidade de maior comprometimento e responsabilidade com o processo de desenvolvimento das aprendizagens, como se pode verificar nestes registros:

- Elogios à professora e à metodologia, a turma tem relação excelente, o que ajuda bastante. No entanto, alguns alunos não se esforçam, sugerimos à turma que se esforcem e participem mais;

- Conteúdo de forma esclarecedora e direta. A turma não cumpre com as atividades, sugerimos que a turma cumpra a sua parte;

- A professora trabalha bem, mas a turma se dispersa, tem desrespeito à fala da professora, é preciso maior concentração. Professora, continue, bom trabalho! (Trechos do texto coletivo dos estudantes lido no conselho de classe e registrados em diário de campo). (Grifos nossos)

Por conseguinte, os docentes, nos seus momentos de fala, também fizeram considerações positivas em relação à turma, mas sempre buscavam enfatizar os problemas denominados de "casos individuais":

- A mudança da turma foi muito boa, diferente do outro consetho, houve realmente uma mudança (P1). 
- Turma muito boa, legal. Não acho que vocês perdem o foco não! (P2).

- Quero agradecer pela avaliação, o empenho da turma, vocês respondem as propostas, agradeço bastante pelo apoio. Existem os casos individuais que extrapolam, é preciso rever um pouco (P3).

- É preciso passar da consciência para a ação de fato. Os casos individuais a gente vai ponderar. É uma turma muito boa (P4).

- O trabalho com a turma em geral é satisfatório, problema são os casos individuais! (P6) (Grifos nossos).

Observa-se que os estudantes colocam no texto coletivo considerações de que a turma ou parte dela está precisando rever atitudes e mudar comportamentos, enquanto que os docentes não aparentam interesse em saber se precisam mudar alguma coisa. Quando as falas dos estudantes são para agradecer e elogiar, consideram-se verdadeiras, de modo que o professor não precisa modificar nada. Quando as falas dos estudantes são para dizer que eles próprios ou os colegas precisam se modificar, que precisam colaborar e cumprir com as atividades, isso é reforçado pelos docentes: "é preciso passar da consciência para a ação de fato”.

Nesse contexto, percebemos que, mesmo que o estudante esteja participando do conselho de classe, ele ainda é o centro das avaliações, seja das avaliações feitas pelo corpo docente, seja das avaliações feitas por eles mesmos (autoavaliação).

No entanto, houve também, nessa reunião, um movimento diferente e interessante: quando elogiada pelos alunos pelo seu modo de trabalhar o conteúdo da disciplina "de forma mais subjetiva e profunda que os outros professores”, a professora respondeu: “Obrigada, eu me sinto muito bem trabalhando com a turma. Vocês se sentem acolhidos diante dos sustos?". Isso demonstra o interesse da docente em saber da turma como eles se sentem em relação às diferentes 
estratégias de ensino utilizadas por ela. Não uma simples troca de elogios, foi um questionamento sobre como os estudantes enxergavam e sentiam esse processo de aprendizagem que estava sendo construído. Esse momento fugiu à regra, saiu do ritual de fala e réplica. Abriu, naquele instante, espaço para que os estudantes falassem mais e sobre algo que não estava programado para o conselho de classe. Os estudantes responderam que sim, que, embora a metodologia fosse bem diferente do que aquelas a que estão acostumados, era interessante e os levava a uma maior reflexão sobre o conteúdo trabalhado.

Num outro momento, ainda no conselho de acompanhamento pedagógico, observamos que os estudantes colocaram que a relação da docente com a turma era estritamente profissional e solicitaram a ela que uma aula fosse separada para tratar sobre "fórmulas". A docente respondeu: Acho que o trabalho tá adequado. Quanto a rever, estamos revendo desde o primeiro dia de aula! Os estudantes riram e o assunto se encerrou nesse mesmo momento. Isso nos remete ao que Dalben (2004) afirma sobre as experiências de conselho de classe participativo que ela observou:

○ que se tem observado com essas experiências é que os alunos falam, apresentam as questões discutidas por eles sobre cada professor, e, em seguida, esse professor, colocado em evidência, justifica suas atitudes, que acabam por ser aceitas pelos alunos, encerrando, assim, os argumentos. O processo, em vez de ser dialógico, transforma-se num bate-bola sem aprofundamento. (DALBEN, 2004, p. 66)

Embora na sala de aula também possam ser colocadas questões como essas, referentes à metodologia docente, é no conselho de classe por meio da participação estudantil que isso é dito oficialmente diante do coletivo, o que pode gerar diálogo e interação entre docente e estudante, mas que também pode reforçar uma relação conflituosa e autoritária entre esses sujeitos. O que é gerado a partir da avaliação que os estudantes fazem sobre os docentes pode servir como reflexão e ajustes da prática docente, mas também pode servir 
para manter a relação de poder já existente em sala de aula. Isso vai depender das concepções que os docentes têm sobre educação e avaliação que fundamentam suas práticas. O que se observa na dinâmica de funcionamento do conselho de classe com participação discente é que nem sempre essa participação consegue promover maior interação entre estudantes e docentes, tampouco consegue promover algum tipo de análise mais profunda em relação ao desenvolvimento das aprendizagens.

Buscando entender de que maneira a participação é compreendida pelos diferentes sujeitos presentes numa reunião de conselho de classe, solicitamos, aos estudantes, docentes e técnicos educacionais participantes da amostra de pesquisa, uma definição do que seria participação. Para os estudantes, a participação não diz respeito apenas ao estar presente numa reunião; ela está relacionada ao sentido de oportunidade para expressar ideias e opiniões, de externar e de discutir os problemas com objetivo de resolvê-los e ainda como forma de colaborar com o grupo:

Expressar sua opinião para o grande grupo, e/ou estar presente para ouvir o que tem a ser falado sobre você. (E6)

É, se você sente que tem algum problema, alguma dificuldade ou até algo positivo que você quer externar, isso sempre pra tentar avançar, sempre tentar melhorar, acho que é isso. (P5)

A participação é a forma mais efetiva de contribuir para que os objetivos do conselho de classe sejam atingidos. Participar não é apenas indo ao conselho, mas também nas discussões sobre os professores em classe, durante a construção dos textos, que ao meu ver é a mais importante. (E3) (Grifos nossos)

Importante refletir que falar ou debater uma questão num determinado grupo não significa necessariamente estar participando. Luck (2013, p. 39) explica que frequentemente, em reuniões escolares com professores, pais ou alunos, é possível perceber que "a reunião é considerada boa quando o nível de 'falação' é elevado e quando os 'participantes' ficam satisfeitos pela oportunidade de se fazerem ouvir". No 
entanto, é necessário compreender que a participação solicita, sim, a presença e a fala, mas fundamentalmente exige o interesse e o compromisso com o que está sendo colocado no grupo, a fim de se alcançarem os objetivos esperados por todos. Para a autora (2013), participar expressando ideias e discutindo só tem efeito quando se alcança o avanço por meio de um processo de compartilhamento de entendimentos sobre o que foi discutido e quando se tomam decisões para enfrentar os desafios e as limitações, compartilhando o poder e a responsabilidade pela sua realização.

Nesse contexto, observamos que a participação dos estudantes no conselho de classe da escola às vezes ganha um sentido de engajamento, que, de acordo com Luck (2013), significa estar envolvido no processo e ainda assumir a responsabilidade de agir com empenho e competência a fim de alcançar os resultados desejados:

A gente teve um caso agora, eu acho que foi no terceiro bimestre ou foi no segundo bimestre, que uma turma tava tendo muitos problemas com um professor específico, e aí, eles tomaram, porque esse problema já vinha acontecendo com outras turmas anteriormente, então eles tomaram a frente pra tentar resolver esse problema de uma forma que eu acho que nunca foi vista no colégio. Então eu acho que cada vez mais, quanto tempo vai passando, mais os alunos ficam cada vez mais engajados, nesse senso de mudança mesmo. De ver um problema e tentar resolver. (E5) (Grifos nossos)

Para os docentes e técnicos educacionais, participação, num sentido geral, varia entre a ideia de participar para falar, para expor ideias ou argumentos, ou participar para ouvir e refletir, e ainda participar para tomar decisões:

Veja, a participação pode se dar de diversas formas na minha perspectiva é, desde a participação enquanto escuta, eu acho que ouvir é uma forma de participar né, e aquela escuta atenta. Não adianta estar presente, mas não estar muito ali, né? Então a participação, ela se dá pela escuta, pela fala, ela se dá pela, através do processo de reflexão sobre aquilo que é escutado, que é falado, né? (P4) 
Bem, participação, a meu ver, não é somente estar presente fisicamente, nem uma participação, se a gente for pensar numa participação de cunho democrático, tá certo? Participação de cunho democrático ela vai envolver a possibilidade do sujeito tomar parte nas decisões. [...] participação democrática necessariamente ela tem que tomar, tem que ter as pessoas envolvidas no processo, se estão interessadas naquele processo, elas têm que ter parte nas decisões. (TE1) (Grifos nossos)

Observa-se que os docentes atribuem à participação um sentido maior, não a restringindo à presença, à expressão ou à discussão de ideias; ela compreende também uma escuta atenta que proporcione uma reflexão acerca do assunto ou problema discutido pelo grupo e também a possibilidade de fazer parte na tomada de decisão. Todos esses aspectos são inerentes à participação; no entanto, é preciso atentar que não basta discutir, refletir ou tomar parte nas decisões, se não houver de fato um comprometimento com acompanhamento e cobrança de realização do que foi decidido.

De um modo geral, segundo os entrevistados dessa pesquisa, a participação dos estudantes no conselho de classe por meio das avaliações sobre a metodologia e sobre a relação com o docente pode favorecer avanços no processo de ensino e aprendizagem, pois, sem as colocações dos estudantes sobre o trabalho docente e sobre as dificuldades que interferem no desenvolvimento do processo de ensino e aprendizagens, o conselho de classe permaneceria limitado ao olhar de apenas um dos sujeitos envolvidos nesse processo, de modo que não seria possível corrigir o que não vem funcionando bem em termos de metodologia. Nesse contexto, observamos que, para docentes e técnicos educacionais, a participação dos estudantes no conselho de classe ganha um papel de relevância porque:

[...] é o momento que eles podem falar pra todos os professores, todos os colegas. É uma instância oficial da escola, um espaço aberto próprio pra que eles é, externalizem o que sentem, o que estão pensando. É importante, se eles não participam, se eles se calam, dá pra o professor ter a ideia de que tá tudo bem $e$ aí você não tem como corrigir o problema, imaginando que 
está tudo bem, como também você não consegue ter uma visão da sala sem a fala deles; fica só na fala dos professores e às vezes para o professor tá tudo bem e a realidade pode ser bem diferente. (P5)

Com certeza, porque, se não tiver o momento da fala dos estudantes, seria algo que apenas o peso dos docentes, seria apenas a fala dos docentes que ia pesar sobre isso, sobre esse momento tão importante e o processo ele se faz por estudantes e docentes $e$ não só pelas ações docentes. Então, é preciso sim ouvir como os estudantes vêm percebendo, como eles vêm percebendo inclusive nossas práticas, porque eles falam delas sobre isso, $e$ como eles vêm se percebendo naquele grupo, no grupo classe, com aquele docente, com aquele campo de conhecimento. Então, se a gente não tiver a devolutiva dos estudantes, é, ficaríamos também, é... (pausa) ficaria uma lacuna nesse processo. (P9) (Grifos nossos)

No entanto, nem sempre esse momento de participação que envolve os estudantes e os docentes no conselho de classe gera uma troca ou um feedback num sentido positivo. Algumas vezes, a participação estudantil pode gerar incômodos. Isso depende do nível da relação entre esses sujeitos e até mesmo da compreensão do educador quanto ao fato de estar sendo avaliado pelos estudantes, os quais podem ser compreendidos como sujeitos não qualificados ou não os mais adequados para avaliar alguém que possui mais conhecimento e experiências que eles:

Pessoalmente não tenho nenhum problema, nenhuma restrição. Agora, às vezes, eu percebo que alguns colegas se sentem incomodados, algumas situações criam um mal-estar e isso deve, no meu entendimento, isso deve ser uma coisa muito tranquila, porque, como qualquer profissional, nós somos sempre sujeitos a processos de avaliação e isso faz parte da própria construção do profissional, da construção da sua atuação pedagógica. Então, vejo isso como muito importante, com muita tranquilidade. (P3)

É uma participação, de certa forma, generalizando, muito boa, né. Salvaguardando algumas exceções, às vezes, tem professores 
que levam para o lado pessoal ou então já estão num processo de desgaste grande com a turma e acaba também trazendo esse desgaste à tona, né, de uma forma não muito madura. Porque uma coisa é o desgaste tá estabelecido e o professor conseguir trazer isso de uma forma tranquila, outra coisa é trazer de, recheado de emoção, né. E, às vezes, essa devolutiva é um pouco mais acalorada e gera alguns rebatimentos, né, pós-conselho, mas, de certa forma, os professores participam de forma interessante. $(\mathrm{P} 4)$

Embora os entrevistados afirmem que as situações de desconforto entre alguns docentes quanto à participação estudantil no conselho de classe sejam esporádicas, compreendemos que a relação estabelecida no primeiro momento do conselho de classe de acompanhamento pedagógico não é uma ação tão fácil de ser realizada pelos docentes:

Como ainda é pouco rara entre nós professores a cultura de autoavaliação, também é raro abrir espaços para sermos avaliados pelos alunos. Fomos educados apenas para julgar os outros. Quando somos submetidos a julgamento do trabalho em que sempre atuamos como soberanos, ficamos abalados em nosso poder. (CRUZ, 2005, p. 53)

Culturalmente, no conselho de classe, é o estudante que é o avaliado, seja em relação ao seu desempenho das aprendizagens seja em termos de atitudes e comportamentos. Colocar o docente na posição de sujeito que tem sua prática e sua relação com a turma avaliadas, ainda que em um curto período de tempo, é uma dinâmica passível de resistência:

A escola, reproduzindo as estruturas sociais e de poder do sistema capitalista, está estruturada com base no incentivo à competição, à superação do outro, ao saber particular, individualizado. A competição entre os profissionais da educação reforça sobremaneira a resistência à aceitação de sugestões ou críticas sobre seu trabalho, principalmente em relação à avaliação, porque envolve questões de autoritarismo e competência na sua disciplina. (HOFFMANN, 2014, p. 140) 
Se, para os docentes, existe uma resistência a receber sugestões ou críticas de seus pares, como apontado por Hoffmann (2014), ela se intensifica quando são os estudantes que fazem esse tipo de avaliação. Nesse sentido, compreendemos a dificuldade de encontrarmos escolas que tenham essa prática de conselho de classe, pois não se trata apenas de instituir, por meio de normativas ou diretrizes, a realização de uma avaliação mais democrática e justa nesse ambiente de avaliação; trata-se, sim, de haver esforço coletivo e transformação de concepções tradicionais de ensino, que determinam as posições hierárquicas e relações desiguais entre docentes e estudantes, em concepções mais humanas de educação e avaliação que tomam o diálogo e o compromisso com a formação do ser integral como elementos que servem para orientar e fundamentar suas práticas.

No entanto, quando a escola se propõe a ter como prática um conselho de classe com a participação dos estudantes, inicia-se a construção de processos mais democráticos, de forma que se consegue transpor barreiras de autoritarismo e caminhar em direção a uma avaliação com maior diálogo e negociação entre estudantes e docentes. Um trecho de entrevista colabora para essa reflexão quando destaca que a participação estudantil no conselho e a avaliação que faz sobre a prática docente são importantes porque ajudam a dirimir o poder que o docente exerce sobre os estudantes:

Os alunos devem participar do processo como acontece entre nós nesse processo de autoavaliação coletiva do comportamento, das atitudes da turma. Como também avaliando o processo de ensino e aprendizagem de cada uma das cadeiras, né. [...] Eu penso que os alunos têm um papel fundamental nisso, até pro professor, tem que se perceber, porque, muitas vezes, o professor pode pensar que é Deus, ou, às vezes, pai de Deus (risos)... (P3).

O surgimento de situações de conflitos é inerente aos espaços participativos: não existem participação nem processos democráticos que não tenham diferentes interesses e expectativas e concepções se intercruzando em torno de uma mesma questão. Nesse contexto, as situações de incômodo ou de conflitos que podem vir a surgir no conselho de 
classe que se propõe a colocar docentes e estudantes num mesmo momento como sujeitos avaliadores e avaliados podem ser compreendidas como momentos de ajustes e até de aprendizagens para ambos, quando consideramos que não somos seres acabados, prontos, mas sim seres em constante evolução, em constante aprendizado (FREIRE, 2015), ${ }^{3}$ principalmente no que diz respeito à relação que estabelecemos com o outro.

Sintetizando o modo como os sujeitos desta pesquisa enxergam a participação dos estudantes no conselho de classe da escola, podemos afirmar que não há divergências nas falas quanto à necessidade e à importância dessa participação, seja para favorecer aspectos relacionados ao avanço das aprendizagens, seja para tratar de problemas de relação entre os sujeitos do ato de ensinar e aprender, como também para favorecer a construção de processos mais democráticos na escola e de uma avaliação da aprendizagem mais formativa, através do feedback, do diálogo e dos acordos que podem se estabelecer entre docentes e estudantes.

Em relação à avaliação das aprendizagens, destacamos, dentre os trechos das entrevistas dos estudantes, a participação deles nesse espaço como importante porque os coloca como sujeitos que também se avaliam, que avaliam a prática docente, que refletem e contribuem, assumindo a corresponsabilidade pelo andamento do processo de ensino e aprendizagem:

Uma das coisas mais importantes do conselho é proporcionar esse momento de troca entre alunos e professores e que a turma ouça os pontos nos quais precisa melhorar e como foi a unidade. Sem os alunos, os conselhos teriam bem menos sentido e daria menos frutos. (E2).

Nada mais justo do que eles poderem contribuir para a melhoria do dia a dia em sala de aula, se autoavaliarem, avaliarem seus professores, falarem dos incômodos e, por que não, elogiar os bons métodos que alguns professores adotam. É de uma importância tremenda que os estudantes participem desse momento; $e ́$ lamentável que em muitas escolas isso não aconteça. (E3)
3 Segundo Freire (2015, p. 102), "Aí se encontram as raízes da educação mesma, como manifestação exclusivamente humana. Isto é, na inconclusão dos homens e na consciência que dela têm. Daí que seja a educação um quefazer permanente". 
Quando questionados se o conselho de classe nessa perspectiva participativa colabora de alguma forma para a avaliação das aprendizagens, os estudantes entrevistados demonstram compreender o conselho de classe como um momento propositivo para mudanças dos docentes e também de si próprios:

Acho que ajuda muito porque a gente reflete se aquilo tá funcionando ou não pra gente, os métodos e tudo mais, a metodologia do professor, as formas que ele tá passando o assunto para gente, tudo isso. Acho que ajuda. Agora assim, né, tem que partir do professor, porque depende muito do diálogo que você for estabelecer e tal, tem que ter o resultado. Eu acho que esse momento é importante, mas o que vem depois também é importante, porque, se você tiver esse momento e o professor ou o aluno não se esforçarem pra mudar a realidade que, tipo, eles refletiram que existia no momento de conselho, aí o conselho não tem sentido, entendeu? Porque o conselho é um momento propositivo; daí as pessoas têm que estar dispostas a mudar depois dele. (E1)

Para Silva (2010, p. 42), a avaliação não é apenas parte do trabalho pedagógico, na materialização do processo de ensinar e aprender; ela é fundamentalmente reguladora desse processo "no prisma de possibilitar ajustes na prática docente, subsidiando possíveis inovações pedagógicas, como na ação discente favorecendo auto-regulações nos percursos de aprendizagem".

Nesse sentido, a dinâmica do conselho de classe em que docentes e estudantes se autoavaliam e avaliam uns aos outros contribui para que ambos se coloquem como sujeitos que podem refletir sobre suas atitudes e práticas e mudar a fim de melhorar o desenvolvimento do processo de ensino e aprendizagem. De acordo com Hadji (2001), a avaliação se torna importante quando atua objetivamente "como um momento forte em um processo de regulação". Ele explica que o esquema que envolve o feedback e o julgamento conduz ao ajuste, de modo que se evidencia, de um lado, que a "avaliação é apenas um momento em um processo geral de condução da ação, mas, de outro, que esse momento é decisivo" (HADJI, 2001, p. 130). Sendo assim, como espaço coletivo de 
avaliação, espera-se que o conselho de classe consiga favorecer a docentes e estudantes a ação e a decisão de mudança frente aos entraves e às dificuldades apresentadas, em prol dos objetivos de aprendizagem que se pretende alcançar.

Na compreensão de avaliação como processo formativo, os docentes entrevistados demonstram compreender o conselho de classe, no momento que conta com a participação dos estudantes, também como um momento em que a avaliação está direcionada não apenas aos estudantes, mas também à prática docente, devido à troca e ao feedback estabelecidos:

É um espaço de troca, um espaço de certa forma de avaliação da prática docente, porque existe um feedback dos alunos no momento que os alunos participam, e essa escuta do aluno no momento do conselho é muito rica. [...] Então, de certa forma, é o momento que o professor reconhece alguma fragilidade do próprio docente, de pactuar o acordo que vai mudar ou que vai começar um processo de mudança, ou então, justificar o porquê de algumas atitudes, né, então é um momento bastante rico, porque é um momento de troca, né. (P4)

Então é importante ele participar, ele dizer o que tá sentindo. Você pode estar achando que seu trabalho está sendo excelente, e muitas vezes eles não falam, por mais que você insista no papo. E, no conselho de classe, ele pode expor, ele expõe e isso é um feedback. Então, ele tem que ter o momento dele, ele tem que falar. [...] Se no conselho de classe forem apenas os professores, isso não faz sentido. Se é um conselho de classe, o aluno tem que estar presente. (P8)

Importante refletir que a mudança na prática docente não vai ser efetivada pelo conselho de classe. Ele por si só não tem a força nem o poder de intervir diretamente na prática de nenhum educador. O que o conselho de classe faz é colocar todas as informações relativas aos estudantes e docentes nessa instância colegiada para que, de forma coletiva, isso possa ser pensado e discutido por todos. No entanto, a reflexão é pessoal, e a mudança em alguma estratégia pedagógica para melhorar o desenvolvimento do processo de 
ensino e aprendizagem é uma decisão e um compromisso de cada docente a partir da sua compreensão sobre o que é avaliar.

Contudo, há de se destacar que, embora alguns participantes da pesquisa afirmem que a participação do estudante no conselho de classe contribui para a reflexão e a mudança da prática docente, seja em relação à metodologia, à didática ou ao modo de avaliar, entre outros aspectos, para outros participantes da pesquisa, é exatamente a ausência de ou a pouca mudança, por parte dos docentes, em suas práticas que diminui ou desmotiva a participação discente no conselho de classe. Isso gera desânimo e desvalorização em relação ao conselho de classe como um espaço de diálogo, de negociação, de acordos e de compromisso com o processo pedagógico:

$E$, assim, às vezes eu entendo os alunos, principalmente no ensino médio, de ficarem desanimados. Porque tem professor que não muda, que a prática não muda, e aí como a gente vai fazer com isso, né? É como se fosse assim, tá fazendo uma coisa mecânica, em alguns casos, reproduzindo um ritual de conselho de classe, mas sabe-se que uns professores não vão mudar sua prática, isso já é uma coisa histórica. [...] Aí acho que eles pensam: Qual a razão de ser disso? Eu vou lá dizer isso e isso, e o professor não vai mudar! Se a gente sabe que é há anos desse jeito, todo mundo fala que é desse jeito! Eu creio que parte, boa parte, do desestímulo é isso. (TE1)

Eu acho que a participação no momento do conselho de classe é se colocar nessa formativa, no processo de aprendizagem. E eu acho que nem todo mundo tem essa compreensão, o que se reflete na falta da adesão no conselho de classe e tal. É... (pausa), mas eu acho que isso também é fruto do, porque eu falei que o conselho de classe é o momento de refletir sobre as coisas que precisam mudar, mas, depois do conselho de classe, a gente precisa mudar, entendeu? E historicamente tem alguns professores que nunca mudam, isso desvaloriza. Desmotiva a gente a participar, a levar aquilo a sério. (E1) 
Quando questionados sobre o que os motiva e os desmotiva a participar dos conselhos de classe do colégio, alguns estudantes responderam:

o que motiva: o fato de ter esse espaço, que de certa forma é privilegiado em relação a outros colégios em que os estudantes praticamente não têm voz para que suas demandas sejam atendidas, os incômodos e os conflitos passam sem ser resolvidos, etc. o que desmotiva: situações que mesmo com o conselho não se resolvem. Coisas mais específicas como a metodologia de certos professores, etc. (E3)

O que motiva: poder expressar sua opinião. 0 que desmotiva: 0 fato de alguns professores não mudarem de atitude. (E6)

Compreendendo a avaliação como processo de acompanhamento e de regulação das aprendizagens e a educação como meio para o desenvolvimento integral do indivíduo, o conselho de classe precisa ser realizado com o objetivo de avaliar para apontar caminhos e elementos suficientes para garantir esse desenvolvimento; nesse sentido, a prática docente precisa estar disponível para passar pelo crivo da reflexão e da mudança.

No entanto, não é apenas ao docente que o conselho de classe pode favorecer reflexões e mudanças; os estudantes, enquanto participantes comprometidos e interessados, também são instigados à reflexão acerca do que ainda precisam modificar e/ou melhorar para alcançarem maior desenvolvimento de suas aprendizagens. Uma vez que se compreende que o objetivo do conselho de classe é realizar o acompanhamento das aprendizagens por meio de uma avaliação processual e formativa, compreende-se que essa tarefa não se restringe apenas ao docente; também cabe aos estudantes a compreensão sobre o seu papel enquanto indivíduos reflexivos e ativos nesse processo de desenvolvimento, como se pode observar nesta fala:

[...] porque eu falei que o conselho de classe é o momento de refletir sobre as coisas que precisam mudar, mas, depois do conselho de classe, a gente precisa mudar, entendeu? (E1) 
Embora não seja perfeito, e não aconteça exatamente como se deseja ou como esteja proposto nas normas e orientações, o conselho de classe, quando realizado com as prerrogativas de buscar coletivamente o sucesso do ensino e das aprendizagens, precisará sempre ser revisto, repensado, reformulado e executado como uma atividade que não se encerra nela mesma, mas que abre possibilidades para que a escola renove suas práticas e reconstrua seu cotidiano em torno de princípios democráticos e de uma avaliação das aprendizagens mais justa e formativa. Diante do que já viemos refletindo sobre o processo da análise dos dados, parece não haver dúvida quanto ao alto grau de importância que é conferido à participação dos estudantes no conselho de classe.

No entanto, observou-se que, no primeiro momento do conselho de classe com a participação dos estudantes, os conflitos e os desgastes gerados pelos comportamentos considerados indesejados ou insuficientes, tanto por parte dos discentes quanto por parte dos docentes, aparecem como tema principal, ficando relegados a segundo plano os temas sobre aprendizagens e avaliação da turma, o que entendemos como uma discussão superficial, sem grandes imersões pedagógicas, didáticas ou buscas de respostas às necessidades que se apresentam. Hoffmann colabora para essa compreensão quando aponta que, no conselho de classe,

Há uma relação por demais estreita entre as discussões que se estabelecem sobre os alunos e as questões de conhecimento. $\bigcirc$ que o aluno não compreende e por que não compreende são questões raramente abordadas nesses momentos, privilegiando-se, demasiadamente, as questões atitudinais. (HOFFMANN, 2014, p. 145)

Ressaltamos que, no segundo momento do conselho para acompanhamento pedagógico, os estudantes são impedidos de participar, visto que, nessa etapa do conselho, serão discutidas questões referentes às aprendizagens e não aprendizagens individuais. Os motivos apresentados pelos docentes entrevistados para a não participação dos estudantes na segunda etapa do conselho de classe envolvem os cuidados 
com a ética e a confidencialidade dos resultados das aprendizagens, como modo de evitar constrangimentos e comentários entre os estudantes.

Importante destacar que a participação dos estudantes ao longo de toda a reunião do conselho de classe foi trazida à tona nas entrevistas de alguns docentes: muitos se posicionam de forma contrária e poucos levantam essa possibilidade, o que nos leva a compreender que essa questão tem sido alvo de alguma reflexão. Ressaltamos que apenas dois docentes se posicionam a favor da participação dos estudantes no conselho de classe para acompanhamento pedagógico nos dois momentos, defendendo que o conselho de classe com a participação dos estudantes para discutir as aprendizagens seria um momento extremamente rico, tanto no sentido da avaliação quanto no sentido da participação. E alegam que é necessário esclarecer que, para os casos individuais em que existissem problemas de aprendizagens ligados a problemas emocionais e/ou familiares, isso não poderia ser colocado diante de todos; poderia ser tratado de modo mais particular numa outra reunião ou ocasião, como é evidenciado na fala abaixo:

Eu acho definidor, se eu entendo que é para o processo de ensino e aprendizagem, para os processos de ensino e aprendizagem. É... (pausa) eu ainda colocaria que os alunos deveriam participar de tudo. Eu fui voto vencido sempre. [Pesquisadora: $O$ aluno participar de todos os momentos?]. Dos dois momentos, de falar do que o outro aprendeu. Porque a responsabilidade do outro [...] pelo limite do outro é do grupo, e o grupo às vezes não ajuda! O grupo teria que se conscientizar de que, aí eu tenho dois ou três alunos que estão com dificuldades, e esses dois, três alunos teriam de fato que ter um apoio, ter um olhar, ter o grupo pra ajudar. Então, lógico, nós não trataríamos de demandas particulares, e aí é a defesa do grupo que não quer que eles fiquem o tempo inteiro. Então, uma pessoa que tem um aluno que tem um problema psiquiátrico "X", e que vem um laudo dos pais, não era ali o momento de se tratar. Teria que se ter uma outra chamada, um outro contato com os professores pra se comunicar. Um momento onde um acontecimento na vida do aluno foi um baque, a perda de alguém muito importante... (pausa) ou 
ali não era o momento de tratar, o SOE ${ }^{4}$ não iria tratar nesse nível em si, no nível do ensino e da aprendizagem, tá certo? E a gente iria talvez se prender muito mais ao pedagógico do que às vezes ao psicologismo que acaba acontecendo, e às vezes, né, acontece. Então eu acho que é muito importante a presença do aluno. (P10)

Destacamos ainda que, embora afirme a possibilidade da participação estudantil em todos os momentos do conselho de classe, existem ressalvas quanto a essa participação:

No meu entendimento, no modelo atual, ele é bastante saudável; talvez a gente teria num futuro, não sei quando, que preparar melhor para que talvez os alunos participassem de toda etapa, eles não participassem apenas de parte do conselho. Eu não sei que tipo de amadurecimento nós teríamos pra que esses alunos participassem no processo de discussão de casos individuais, não sei como poderia ser isso. Talvez no futuro pudessem participar integralmente do conselho de classe, inclusive daquele que decide pela retenção ou promoção. Mas repito que isso precisa de um longo processo de amadurecimento para que haja participação equitativa e objetiva de todos, inclusive dos alunos. [Pesquisadora: Já existiu na escola algum movimento de participação nesse sentido?]. Não tenho conhecimento! (P3)

Compreendemos que o Colégio de Aplicação da UFPE, por se apresentar como uma escola de aplicação de teorias e conhecimentos, que atua como espaço de experimentação e fomentação de projetos e pesquisas, poderia, talvez por um processo de bastante análise e estudo, fazer a experiência de possibilitar a presença dos estudantes de uma turma numa reunião de conselho de classe durante todos os momentos. Nesse sentido, haveria informações mais concretas se de fato os estudantes podem ou não participar de todo um conselho de classe para acompanhamento pedagógico, no qual, para além da discussão sobre comportamentos, atitudes e relação docente-turma, o processo de ensino e aprendizagem poderia ser pensado e analisado pelas duas partes que compõem esse processo - docentes e estudantes. 


\section{CONSIDERAÇÕES}

O conselho de classe com a participação dos estudantes se apresenta como uma prática significativa e transformadora da cultura dominante de avaliação escolar. No entanto, observou-se que a participação dos estudantes no primeiro momento do conselho de classe não consegue ir além das discussões sobre atitudes e comportamentos deles e dos docentes. E, embora os entrevistados informem que essa dinâmica participativa favorece o processo de ensino e aprendizagem, na medida em que as avaliações dos discentes sobre os docentes e vice-versa são colocadas no coletivo, é possível perceber que o que é avaliado por esses sujeitos gira em torno dos conflitos e dos desgastes gerados pelos comportamentos considerados indesejados ou insuficientes, tanto por parte dos discentes quanto por parte dos docentes, deixando-se em segundo plano as questões sobre as aprendizagens, o que entendemos ser uma discussão superficial, sem grandes imersões pedagógicas, didáticas e sem buscas por respostas às necessidades que se apresentam.

Embora o conselho de classe com a dinâmica participativa nem sempre consiga alcançar efeitos mais significativos para a melhoria do desenvolvimento do processo de ensino e aprendizagem, é interessante pontuar que, mesmo com o movimento de continuidade e descontinuidade, de avanços e retrocessos, esse tipo de organização e de funcionamento de conselho de classe consegue promover a construção de uma cultura mais democrática e participativa na escola, como também colabora para que a avaliação das aprendizagens esteja ligada aos princípios do diálogo, da negociação e da regulação.

Por essas possibilidades e se acreditamos numa educação que possa favorecer a formação de indivíduos críticos, reflexivos, autônomos, cidadãos, há de se pensar em incentivar e construir na escola uma cultura avaliativa que conte com a participação dos sujeitos envolvidos com o processo de ensino e aprendizagem. Nesse contexto, o conselho de classe com a participação dos estudantes é um exercício de avaliação democrática possível e com relativo êxito nesse caso específico.

E, embora possamos correr o risco de duvidar que a prática de um conselho de classe com essa dinâmica de 
funcionamento e organização, como foi observado nesse estudo de caso, possa ser adotada em outras escolas públicas, pelas diferenças dos contextos sociais e econômicos nas quais estão inseridas, arriscamo-nos a afirmar que isso depende do interesse dos sujeitos que fazem a gestão da escola. Pensar a escola pública que tenha como objetivo a formação integral de seus estudantes é pensar em fomentar processos democráticos via participação plena de seus integrantes, o que inclui a produção de conhecimento, o acompanhamento e a avaliação das aprendizagens.

\section{REFERÊNCIAS}

ÁLVAREZ MÉNDEZ, Juan Manuel. Avaliar para conhecer, examinar para excluir. Tradução de Magda Schwartzhaupt Chaves. Porto Alegre: Artmed, 2002.

BARDIN, Laurence. Análise de conteúdo. Tradução de Luís Antero Reto e Augusto Pinheiro. ed. revista e actualizada. Lisboa, Portugal: Edições 70, LDA, 2009.

CHIZZOTTI, Antonio. Pesquisa em ciências humanas e sociais. 8. ed. São Paulo: Cortez, 2006.

CRUZ, Carlos Henrique Carrilho. Conselho de classe: espaço de diagnóstico da prática educativa escolar. 3. ed. São Paulo: Edições Loyola, 2015.

DALBEN, Ângela Imaculada Loureiro de Freitas. Conselhos de classe e avaliação: perspectivas na gestão pedagógica da escola. Campinas, SP: Papirus, 2004.

FREIRE, Paulo. Pedagogia do oprimido. 59. ed. rev. e atual. Rio de Janeiro: Paz e Terra, 2015.

GIL, Antonio Carlos. Como elaborar projetos de pesquisa. 5. ed. São Paulo: Atlas, 2010.

HADJI, Charles. Avaliação desmistificada. Tradução de Patrícia C. Ramos. Porto Alegre: Artmed, 2001.

HOFFMANN, Jussara. Avaliação mediadora: uma prática em construção da pré-escola à universidade. 33. ed. Porto Alegre: Mediação, 2014.

LUCK, Heloísa. A gestão participativa na escola. 11. ed. Petrópolis, RJ: Vozes, 2013. (Séries Cadernos de Gestão).

LUCKESI, Cipriano Carlos. Avaliação da aprendizagem escolar: estudos e proposições. 19. ed. São Paulo: Cortez, 2008.

MAGNATA, Rubia Cavalcante Vicente; SANTOS, Ana Lúcia Félix dos. Avaliação formativa da aprendizagem: a experiência do conselho de classe. Estudos em Avaliação Educacional, São Paulo, v. 26, n. 63, p. 768-802, set./dez. 2015. 
PERRENOUD, Philippe. Avaliação: da excelência à regulação das aprendizagens - entre duas lógicas. Tradução de Patrícia Chittoni Ramos. Porto Alegre: Artes Médicas Sul, 1999.

SANTOS, Almir Paulo dos. Aluno sujeito da avaliação: conselho de classe participativo como instância de reflexão. Roteiro, Joaçaba, SC, v. 35, n. 2, p. 299-318, jul./dez. 2010. Disponível em: <http://www.periodicos.capes.gov. br>. Acesso em: 11 fev. 2016.

SILVA, Janssen Felipe da. Avaliação educacional do trabalho pedagógico docente: fundamentos teóricos e implicações metodológicas. In: CRUZ, Fátima Maria Leite (Org.). Teorias e práticas em avaliação. Recife: Editora Universitária da UFPE, 2010.

Recebido em: 18 AGOSTO 2017

Aprovado para publicação em: 12 JUNHO 2018 